Artículo de reflexión

Cuestiones de Filosofía

ISSN: 0123-5095

E-ISSN: 2389-9441

Vol. $7-\mathrm{N}^{\mathrm{o}} 29$

Julio - diciembre, año 2021

pp. 79-99

\title{
El cuidado de sí en Foucault: capitalismo, economía psíquica y subjetividad
}

\author{
Care of the self in Foucault: Capitalism, psychic \\ economy and subjectivity
}

Christian Guillermo Gómez Vargas ${ }^{1}$

Universidad Nacional Autónoma de México

Recepción: 16 de julio del 2021

Evaluación: 26 de octubre del 2021

Aceptación: 28 de octubre del 2021

Doctor en filosofía UNAM-ITESM, Estado de México.

Correo electrónico: elespiritudeltiempo1@gmail.com

Gómez, C. (2021). El cuidado de sí en Foucault: capitalismo, economía psíquica y

subjetividad. Cuestiones de Filosofía, 7 (29), 79-99. 


\title{
Resumen
}

El presente artículo parte de la reflexión en torno al concepto del cuidado de sí en Foucault, que estriba, en términos éticos, en la noción de trabajo sobre sí mismo. Dicha perspectiva ética representa una forma de resistencia y disrupción contra los modelos de articulación de sentido, cristalización del valor, disciplinamiento y disposiciones de acción, que se despliegan en un circuito de prácticas alienantes que confeccionan la subjetividad del individuo contemporáneo. Subjetividad para cuya confección se consideran esquemas de la economía psíquica, hegemónica y vigente, que a su vez sostienen los modos de producción de la actualidad. Propiedades psíquicas entre las que destacan síntomas que se mueven en la órbita clínica del narcisismo, el cual se encuentra enraizado como una de las caras fenoménicas del fetichismo. Asimismo, este último se encuentra en consonancia con la racionalidad técnica, propia de la modernidad, que se desplaza y construye en un paradigma que ostenta nociones y orientaciones de crecimiento y progreso ilimitado. Formaciones fantasiosas que se materializan en un entramado de explotación, producción y consumo fundado en términos de poder-saber. La ilusión de la omnipotencia técnica adquiere, entonces, aparente condición de posibilidad mediante la intrusión de diferentes tecnologías, saberes e instrumentos, que favorecen el andamiaje en el que se erigen las representaciones de explicación y significado que fundamentan la subjetividad vigente y válida.

Palabras clave: cuidado de sí, fetichismo, subjetividad, Umwelt, narcisismo.

\begin{abstract}
This article comes from the reflection regarding Foucault's concept of "care of the self", which consists of the work on one self, in ethical terms. Such an ethical perspective portrays a setting of resistance and disruption against meaning construction models, established values, authorities and action directives which become unwrapped in a series of alienating practices that shape the subjectivity of the contemporary person. In order to craft this subjectivity, schemes from the current and hegemonic psychic economy are taken into consideration. Such schemes unfold and hold up nowadays production means. Among other psychic features, there are certain symptoms that are clinically similar to narcissism, condition whose traits are rooted in one of the phenomenal sides of fetishism. Accordingly, modernity's technical rationality becomes a paradigm built upon unlimited growth and development.
\end{abstract}


Fantasy formations that materialize under a model of exploitation, production and consumption practices founded in terms of power-knowledge. Thus, the illusion of technical omnipotence acquires an apparent condition of possibility through the intrusion of different technologies, performances, knowledge and instruments, which favor the frameworks in which the representations of explanation and meaning that underlie the current and valid subjectivity are erected.

Key words: care of the self, fetishism, subjectivity, Umwelt, narcissism. 


\section{Introducción}

Antropólogos del cerebro asumen que la subjetividad y su confección se articula como un conjunto que se desenvuelve en una red compleja de condiciones internas y externas al propio cerebro (Bartra, 2014). Esta noción es disruptiva del modelo tradicional gestado en los umbrales de la modernidad, el cual se esgrimía desde el planteamiento dualista que se despliega entre la dicotomía de la res cogita y la res extensa, puesto que en dicha concepción clásica no existe una clara conexión entre pensamiento y mundo externo (2014). Para la antropología cerebral la subjetividad se conforma, entonces, a partir de un sistema complejo que se sedimenta en prácticas culturales, interacciones con el medio, relaciones de un sistema que se entreteje entre saberes internos y externos. Se trata de un sistema de redes cerebrales que se extienden más allá del cerebro y que mediante formaciones semióticas, representaciones e interacciones con el medio exterior, se conjuga y fundamenta erigiendo la subjetividad. Esta condición es denominada por Bartra procesos "exocerebrales" (2014).

La construcción de la subjetividad no obedece, por tanto, solo a estructuras neuronales, condiciones químicas y físicas de la topografía del propio cerebro, sino que se encuentra modulada e inscrita en un andamiaje de relaciones e interacciones sociales y culturales (2014), de modo que la edificación de la subjetividad-formación que en Lacan refiere directamente a la función del yo (je), y su relación con el estadio del espejo- describe que los seres humanos en sus primeras experiencias neonatales crean un contorno espacial con base en sus movimientos, demandas libidinales y representaciones iniciales. Dicha edificación incipiente de la subjetividad articula la relación entre el interior y el exterior del sujeto. Tal operación de la subjetividad modula, entonces, un armazón, complejo virtual, que designa la mediación entre el cuerpo, los objetos exteriores y las personas que se encuentran alrededor ${ }^{2}$. De este modo la subjetividad articula una relación del organismo con la realidad exterior (Umwelt) (Lacan, 2009, p. 102). Esta relación de la subjetividad con su medio exterior coordina, a su vez, las formas de inteligibilidad, totalidad (Gestalt)

\footnotetext{
${ }^{2}$ La descripción que hace Lacan de la formación del estadio del espejo se conjuga en la tríada imaginario-simbólico-real, en la que el 'yo' no es más que la respuesta a la relación de la imagen de dicha tríada (espejo). La formación del estadio del espejo en Lacan describe la prematuración específica de los momentos iniciales de la vida, es decir, las formaciones que van precisando la completud corporal, la coordinación, etc., con la exterioridad (Lacan, 2009).
} 
y sentido (2009). Se trata de la cristalización de la red de la subjetividad de la génesis psicológica entre el yo y el mundo-, es decir, la formación del armazón que posibilita el andamiaje de lo que denominamos lo real.

La descripción que hace Lacan de la formación del yo (je) es semejante a la de la 'antropología cerebral' cuando ésta mienta que el cerebro es equivalente a un potente procesador vectorial que interioriza flujos de información que gravitan en el medio ambiente y que fungen como andamios sociales, informaciones que se cristalizan en una dialéctica que se dilata en una tensión permanente que enlaza condiciones fenoménicas del cerebro y su contorno sociocultural (Bartra, 2014). Así, se establece una ecodependencia mental isomórfica que se extiende en un sistema amplio que incluye condiciones biológicas, circunstancias ambientales y entorno social.

\section{Cristalización fetichista de la dinámica social}

En torno a la obra de Marx, uno de los tópicos más ignorados durante mucho tiempo fue el concepto de fetichismo de la mercancía. No obstante, para el teórico Isaak Rubin, predecesor de la nueva Marx-Lektüre en Alemania, el concepto de fetichismo de la mercancía constituye uno de los componentes esenciales en torno a la crítica de la economía capitalista (Aragüés, 2015). De la misma manera, Anselm Jappe hace una recuperación y reinterpretación de la obra de Marx, al sostener que dicho concepto conecta los aparentes tejidos inconexos y distantes de nuestras realidades sociales, enlazadas por una síntesis social. Al respecto afirma: "el capitalismo es como un brujo que se viera forzado a arrojar todo el mundo concreto al caldero de la mercantilización para evitar que todo se pare" (2019, p. 13). Es decir que el carácter misterioso de la mercancía, sostenido por Marx, proyecta sus potentes rayos ante los hombres y refleja de ese modo los vínculos de su carácter social, indica que el valor de las mercancías brota como si se tratara de una virtud propia del carácter material de los objetos (Marx, 2010). Sin embargo, el valor estriba en las diferentes relaciones sociales y vínculos que se establecen entre los distintos productores, es decir, entre los diferentes involucrados en los procesos productivos -obreros, consumidores y modos de producción. De dichas redes y sus eclosiones se establecen los signos que rigen los modelos de valor social, única fuente de donde puede emanar todo fenómeno de valor (2010). Estas dinámicas de soporte y andamiaje crean de esta manera un circuito de relaciones de ratificación, jerarquización y saber; 
dicho de otro modo, un conglomerado de símbolos y signos que fundamentan las configuraciones que adopta la estructura social a partir de la cual el sujeto se yergue y configura.

En este entramado de ideas aparece la noción de "sujeto automático", que emana del concepto de fetichismo de la mercancía, pese a que éste haya aparecido una sola vez anunciado en la obra de Marx (Jappe, 2019). Dicha concepción marxista de "sujeto automático" indica que el sujeto interioriza las formas de valor que soportan el tejido social y sus modos de producción en una serie de vínculos de coherencia. Al respecto Jappe sostiene:

El valor pasa constantemente de una forma a otra sin perderse en este movimiento, transformándose así en un sujeto automático. En una sociedad en la que domina el fetichismo de la mercancía, no puede haber un verdadero sujeto humano: es el valor, en sus metamorfosis (mercancía y dinero), el que constituye el verdadero sujeto. Los «sujetos» humanos van a remolque suyo, son sus ejecutores y sus «funcionarios», los «súbditos» del sujeto automático (p. 31).

Para Jappe es posible fundar una historia psíquica reactiva en la formación del sujeto, con base en el concepto de fetichismo de la mercancía, que engloba las diferentes relaciones en un ecosistema de redes fundado por los modos de producción, sus cristalizaciones de valor, las circulaciones de sentido, las formas de validez, la ratificación de prácticas culturales etc., lo que genera un circuito de legitimación que en conjunto se denomina superestructura capitalista. De esta manera, dicho contorno se concreta en las formas de "un hecho social total", en el que los modos de producción y su fetichismo pueden funcionar sin una operación de coacción ostensiva -dialéctica del amo y el esclavo-, y si mediante formas de seducción, control social y normalización; preámbulo de lo que, en palabras de Bauman, conduce las sociedades modernas hacia su liquidez (2003). En estas sociedades la autoridad y el poder no aparecen como representantes fijos y anquilosados, sino que se trata más bien de una propiedad que "emana" de los propios intersticios de la superestructura, puesto que "el verdadero autoritarismo es el del «sujeto automático»: el valor y su lógica fetichista” (Jappe, 2019, p.133). Se trata, entonces, de una economía psíquica que, en tanto sostiene la subjetividad, sustenta los propios mecanismos de la estructura económico-social. Una forma de materialización de la experiencia social que requiere de formas de legitimación, reproducción y simbolización, es decir, que se trata de los 
mecanismos que se constriñen basados en los modos de producción vigentes. Esto genera un doble movimiento, en el que la subjetividad se engendra con base en los tránsitos y pliegues de dicho desenvolvimiento social. Es así que se crean las condiciones "exocerebrales" (Umwelt) de confirmación y sedimento de la experiencia, de modo que se produce una ecodependencia entre el interior y el exterior del sujeto. Esto equivale a una forma de unión y quiebre en la formación reactiva de la experiencia, que cobra la concreción de la subjetividad; la subjetividad, a su vez, conforma las ordenaciones y concepciones que articulan y fundamentan la vivencia exterior. El sujeto se precipita, por tanto, en dispositivos de dominación anónima e impersonal, desplazando su poder y, por tanto, su libertad, al engranaje y superestructura de legitimación, es decir, deviene "sujeto automático". En dicha dinámica, el sujeto se yergue como un mero "funcionario de la valorización", como sostiene Jappe (2019), en el que el poder ya no pertenece al sujeto, sino al dispositivo. Esta dinámica indica que el sujeto ha devenido un "subhombre" enajenado, anónimo, reemplazable; un mero flujo fantasmal carente de dignidad y valor, allende de la macro estructura de sentido capitalista, semejante al individuo que describe Arendt (2006) que encarna la banalidad del mal.

\section{Progreso ilimitado, síntoma persistente de la modernidad}

François Flahault (2013) afirma que el programa de la modernidad se articula con una nueva concepción del conocimiento. Se trata de un pensamiento centrado en la acción más que en la especulación, esgrimido en la vita activa más que en la contemplativa, y emplea su accionar en términos de poder, en tanto que operación y gestión de las leyes que yacen ocultas en el fondo de la naturaleza, para de este modo ponerlas al servicio de las necesidades humanas. El programa de conocimiento de la modernidad centra su especulación en la lógica del progreso, el cual termina consintiendo al servicio de la lógica capitalista (Flahault, 2013). Dicho programa estriba en que el "saber" consiste en extraer las "energías nucleares" del mundo y ponerlas al servicio de las necesidades humanas, hasta el grado ilusorio de desaparecer la misma esfera de la necesidad (Weil, 2014). Se trata de una agenda de saberes que se agota en controlar los elementos, lo invisible, las leyes de la naturaleza, en un intento de dominación para servir a lo visible, pues conociendo las propiedades de los objetos con una exacta precisión, así como los artesanos conocen sus diversos oficios, el programa gradual era convertirse en dueños y señores de la naturaleza (Flahault, 2013). No obstante, dicho paradigma de 
conocimiento se inscribía en una noción de la fuerza (force) como detonante del conocimiento, entendido éste en términos de un mecanismo de poder que extrae de la naturaleza sus secretos más profundos y los pone al servicio de la técnica. Empero, siguiendo a Simone Weil (2014), los ideales del progreso se han establecido como hilo conductor de la narración histórica de Occidente, estructurando los acontecimientos de los últimos siglos en forma de progreso técnico, hasta la pretensión de alcanzar su avance ilimitado. Sin embargo, dicho programa, pese a sus beneficios, también ha generado incontable miseria física, económica y moral de millones de seres humanos de diferentes épocas y latitudes, así como ha producido daños ecológicos incontables a nivel planetario. Dicha idea de progreso ilimitado se posiciona al mismo nivel de los discursos encantados, de los que la modernidad suponía su superación (2014). No obstante, atendemos que dicha cualidad y peligro que entraña el supuesto programa del progreso ilimitado, implementado en sistemas limitados como lo son el planetario y la dinámica social, ya había sido advertido en el pensamiento griego y latino, desde diferentes tradiciones tales como la épica trágica. Encontramos ejemplos de la enunciación de dicho peligro en personajes como Erisictón de Tesalia, Edipo, Prometeo, Dédalo etc., que encarnan la desmesura, la falta, la indeterminación, lo monstruoso, lo contra-natura, cuyo fallo se pagaba mediante el ingreso de la némesis, de la justicia retributiva, que supone el ingreso del límite y la armonía frente a la desmesura y lo ilimitado. Así también, encontramos tal notificación del riesgo de la noción de lo ilimitado como mecanismo racional, en pensadores como Aristóteles (1988), cuando el estagirita hace la distinción entre la economía crematística y doméstica, considerando que la primera obedece a una noción irracional debido a su carácter ateleológico y tautológico, puesto que su función no estriba en satisfacer necesidades humanas, como sucede con la economía doméstica, sino que se agota en su propio movimiento, de modo que la economía crematística tiende a una dinámica sin límites fijos, autotélicos, ilimitada y, por tanto, pervirtiendo su propia función (1988). Atendemos también que dicho ímpetu de lo ilimitado aparece como una excitación constante del pensamiento moderno que deviene modelo de orientación y arquetipo de buena parte de los discursos y sus manifestaciones culturales más elocuentes; figuras de lo ilimitado que encontramos en ámbitos como el político, el mercantil, el científico, el tecnológico, el militar, etc. (Weil, 2014). 


\section{Economía psíquica: fetichismo y narcisismo, síntomas de lo ilimitado}

La visión ilusoria de la omnipotencia técnica, marca constante de la modernidad, posee un parecido de familia con una cualidad psíquica concebida en términos de narcisismo, cualidad psíquica introducida por Freud en Introducción al narcisismo de 1914, en el cual designa al yo real (Real-Ich) como la dimensión durante la cual el neonato habría sido objeto de las primeras satisfacciones narcisistas. Posteriormente, el individuo ya desarrollado psíquicamente tiende a querer reencontrarse con ese yo ideal que alude a un estado característico de la llamada omnipotencia infantil (Freud,1984) $)^{3}$ denomina narcicismo', 'libido del yo', a una estructura psíquica que aún se encuentra inmadura y en la que el neonato no puede distinguir entre los límites de su propio cuerpo, pulsión y goce, de los objetos que avienen del mundo exterior. El neonato se encuentra, por tanto, enteramente vulnerable, impotente, aunque gestiona libidinalmente una sensación de omnipotencia, al confundir la carencia de determinaciones fenoménicas de su cuerpo con las propias condiciones estructurales que satisfacen su pulsión. Se trata de una ilusión de omnipotencia en la que no hay límites entre su cuerpo y los afectos, pulsiones y goces exteriores ${ }^{4}$. Desde la perspectiva psicoanalítica, el narcisismo clínico no apunta a una fortaleza del yo -fundamentación del amor propio y a una psique saludable-, sino, por el contrario, a una debilidad del yo en la que el individuo "retorna" a un estado psíquico arcaico del desarrollo "pre-edípico". La superación del estado pre-edípico es un estadio que da acceso a las "relaciones de objeto" (Jappe, 2019, p. 35). En este

\footnotetext{
3 Omnipotencia infantil que para Lacan alude a la regulación del infante con la madre que comprenderá la noción de imago (estadio del espejo); regulación que en un principio temprano es descoordinada, es decir, desdibujada entre la relación fenoménica del cuerpo del infante y la gratificación de la pulsión procurada por la madre ante las demandas vitales. Es la regulación en la que el niño desvalido confunde la relación entre el je y su medio (Umwelt). Dicha descoordinación alude, por tanto, a una relación pre-edípica en la que aún se encuentra inmadura la vida psicológica del neonato (Lacan, 2009).

${ }^{4}$ Sin embargo, entendemos que la concepción del narcisismo es heteróclita y no unívoca en su definición, debido al amplio espectro del que goza el término en la literatura psicoanalítica. No obstante, el propio Freud distinguía entre un narcisismo primario y secundario (Laplanche y Pontalis, 1996, p. 230): el narcisismo primario es un elemento útil para la conformación del yo y la identidad psíquica; el secundario, por otra parte, refiere al retorno de estados psíquicos inmaduros y pre-edípicos, por lo que se sigue que el agente no goza de una buena relación objetual, puesto que toda relación sana requiere de un vínculo de objetos y ésta supone la posibilidad de ciertos grados del abandono del yo. No obstante, debido a la heterogeneidad del concepto de narcisismo, otros autores dudan incluso de su propia existencia (pp. 230-231).
} 
sentido, el narcisista se mueve en un circuito contrario al de un sedimento fuerte y glorioso, es decir, se encuentra vaciado, incapaz de "(...) eclosionar en relaciones auténticas con los objetos y las personas exteriores; se limita a revivir una y otra vez las mismas pulsiones primitivas" (p. 35).

Para Anselm Jappe (2019) se puede notar un parecido de familia psíquico que nos sugieren nuestros mecanismos tecnológicos, científicos, militares, económicos; asimismo, también algunas prácticas de consumo. Estos mecanismos impelen a la ilusión del progreso perenne, omnipotencia infantil, cualidad que alude al concepto del narcisismo. Tales mecanismos adquieren la representación de posibles satisfactores de todas las necesidades y demandas humanas, de modo que la subjetividad cae en términos de dependencia psíquica ante dichos satisfactores:

A cambio del confort adquirido, aceptamos dependencias muy fuertes de tipo infantil, e incluso una cierta impotencia, y nos encontramos en el «estado de desamparo» del recién nacido, incapaz de sobrevivir ni un solo día sin la ayuda de un tercero. Es la negación de la dependencia la que crea formas de dependencia históricamente inéditas; es la fantasía de omnipotencia la que crea la impotencia (p. 158).

Así, la fantasía de la omnipotencia conduce a formas de dependencia psíquica del tipo infantil; ilusión que se alude en la pulsión de la omnipotencia desmedida por la negación de una dependencia exterior, que para Jappe (2019) es sugerida, ilusoriamente como todo narcisismo, por los procesos técnicos, económicos, científicos y de consumo de nuestras sociedades. Por lo tanto, y dicho lo anterior, se advierte una fantasía que supone una economía psíquica constituida fenoménicamente por un fondo narcisista, que es sugerido por los procesos técnicos y tecnológicos que asemejan algunas propiedades de la "magia", en la cual las operaciones se llevan a cabo con solo apretar un botón o pisar un acelerador, en las que el sujeto "experimenta un enorme poder" (p. 14).

Una condición que avisa la impotencia del sujeto individual al dar cuenta de sí, sin la intervención de la macroestructura técnica, tecnológica, operativa, de nuestras sociedades generadoras de significado y valor. Sociedades en las que el individuo muestra su entera vulnerabilidad sin dichos procesos de génesis axiológica. Pero también se gesta la absoluta ilusión de omnipotencia a través de dichos procesos técnicos -tales como los artefactos culturales, los saberes 
dominantes y los dispositivos tecnológicos- que apuntan directamente al fenómeno del fetichismo de la mercancía. Esta operación fetichista consiente símbolos y orientaciones tales como el mercado, el dinero, los modos de producción, la técnica, el consumo, que soportan, estructuran y solidifican la subjetividad, pero también fundamentan las formas en las que el individuo habita su cotidianeidad social.

Para Jappe los conceptos de "narcisismo y fetichismo de la mercancía" se mueven en el mismo circuito de explicación, de modo tal que tienen desarrollos en paralelo. Se trata de dos caras de la misma forma social, es decir, fenómenos isomórficos (2019), puesto que el fenómeno del narcisismo para Jappe (2019) se articula y configura con base en el despliegue del sujeto que atiende a las estructuras vigentes de ratificación, dirección y concreción axiológica. Dicho de otro modo, se trata de un plexo de signos fetichistas de la mercancía que soportan el reticulado en el que gravita y se desenvuelve el sujeto, así también las formas que componen su subjetividad, de modo que tales signos fetichistas conjuran una síntesis social total, o hecho social total. Esto posibilita el movimiento y concreción de las sociedades actuales, que mantienen en su base la figura del progreso perenne mediante la etiología de la omnipotencia técnica. Lo anterior puede evidenciarse a través del entusiasmo tecnoidolátrico, como es el frenesí por los programas espaciales, los progresos de la medicina, los mecanismos tecnológicos y técnicos etc., pero en cuya base se encuentra la impotencia del propio sujeto frente a los dispositivos de la macroestructura fetichista, que generan validez, ordenación y significado: "lo que está siempre en juego es la lucha contra los sentimientos de impotencia que reactivan la situación de impotencia del lactante" (p. 157).

Estos dispositivos de la macroestructura fetichista representan estructuras generadoras de valor, que sustentan los entramados de la dinámica social y, asimismo, confeccionan un tipo de sujeto que permite la reproductibilidad del propio mecanismo. Adviene el sujeto automático, funcionario del valor, que sostiene los procesos simbólicos configurando todo un andamiaje y ecosistema de relaciones de ratificación: de normalización.

Procesos de validación de la macroestructura que, a su vez, posibilitan la fantasía que se gesta entre la absoluta impotencia y la omnipotencia que sugieren los modos de producción y sus dispositivos, como son el uso del dinero, las aplicaciones tecnológicas, la ciencia, la economía, la información, los artificios técnicos, etc. Estos procesos de validación equivalen, entonces, 
a formas de soporte estructural, material y simbólico. Se trata de un automovimiento de abstracción en el que el capital -que Marx describe en el fetichismo de la mercancía- no solo se muestra como un fenómeno idealista, sino que se inscribe en un acontecimiento "concreto", puesto que parece como si de las mercancías brotara una ordenación y circulación de sentido que sugieren las diferentes formas de valor que imbrican el tejido y plexo de los vínculos sociales. Estos últimos eclosionan en una lógica que se agota en su propio circuito, en el que las determinaciones de las diferentes manifestaciones fenoménicas del capital, pierden su forma y se ven sometidas a no ser más que el soporte de la propia corriente autotélica del modo de producción vigente. Estas manifestaciones fenoménicas se agotan en un contorno que se mueve en la forma de explotación-producción-consumoinversión retornando ilimitadamente a su ciclo, en el que el capital aumenta para invertirse, cobrando condiciones diversas, tales como el dinero, las mercancías, etc., pero que, a la saga, conducirá al mismo recorrido tautológico. Una espiral con propensión identitaria que cobra siluetas totalitarias; condición que se caracteriza como un rasgo "estructural" y civilizatorio de nuestra época. Se trata de formas del fetichismo contemporáneo de nuestras sociedades, que conducen, en último término, a la ineluctable destrucción del propio mecanismo y sus condiciones de posibilidad, lo cual alude a un ciclo de explotación-producción-consumo-inversión del capital que se instala de manera desmesurada, agotando sus condiciones materiales, simbólicas y sociales. Este proceso supone la implementación de una lógica ilimitada en un sistema limitado, como representan las dimensiones humana, social y planetaria. No obstante, dicha corriente orienta el programa del curso de la historia del progreso de la sociedad capitalista, pero también conduce a verdaderas derivas psíquicas suicidas del individuo, que se manifiestan en malestares como el burnout y la depresión ${ }^{5}$.

\footnotetext{
Fenómenos psíquicos como la depresión y el burnout, que para el filósofo surcoreano Byung-Chul Han (2017) representan patologías psicológicas características de la actualidad. Estos fenómenos representan precipitaciones psíquicas específicas de las sociedades del rendimiento (können), que a diferencia de las sociedades represivas (nicht dürfen), conducen a pautas de acción en las que el individuo internaliza, debido a mecanismos de economía psíquica con las que operan dichas sociedades, el rendimiento maximalista. A diferencia de las sociedades que se despliegan en la idea del deber y la represión, como sucedía con las sociedades "freudianas o fordistas", siguiendo a Han, las sociedades actuales se orientan por nociones productivistas neoliberales de generación de valor, es decir, desde la intervención de una economía que impele a una psique flexible, la cual coincide con las formas de liquidez; dicho de otro modo, la falta de certidumbre que se desenvuelve entre la impotencia (vulnerabilidad) y la ilusión de omnipotencia del sujeto contemporáneo.
} 
Así, el sujeto contemporáneo coincide con el señalamiento de Dufour (2007) en tanto que el sujeto autónomo se disuelve en las nuevas correspondencias de los "grandes Sujetos", en los modos neoliberales de las demandas de generación de valor que engendra las condiciones de ratificación social y de sentido (p. 87). Esto quiere decir que se trata de subjetividades que cobran la forma del verdadero motor del capitalismo actual, que se desplazan bajo la ilusoria condición de la omnipotencia y dependencia ante los dispositivos de orientación y significado. Al respecto Beatriz Preciado sostiene:

El verdadero motor del capitalismo actual es el control farmacopornográfico de la subjetividad, cuyos productos son la serotonina, la testosterona, los antiácidos, la cortisona, los antibióticos, el estradiol, el alcohol y el tabaco, la morfina, la insulina, la cocaína, (...) y todo aquel complejo material-virtual que puede ayudar a la producción de estados mentales y psicosomáticos de excitación, relajación y descarga, de omnipotencia y de total control (2008, p. 30).

El control de la subjetividad, como sostiene Preciado (2008), alude a estados mentales enraizados en artefactos químicos, biológicos, tecnológicos y farmacéuticos. La carencia de tales artefactos despoja al individuo de todo poder -ilusorio- y lo arroja a una vulnerabilidad infantil que imita la estructura narcisista clínica, tal como la entendían Freud (1984) y Lacan (2009). De esta manera, de la operación de dichos dispositivos se articulan formas sutiles de disciplinamiento, que aluden a una economía psíquica basada en el hedonismo, en la excitación-frustración, que junto al negocio global de la guerra, la industria farmacéutica, en tanto que extensión del aparato científico, o a través del tráfico de drogas legales e ilegales, devienen arquetipo de todo valor (2008). Dicho de otro modo, se trata de un modelo que se instaura sin la posibilidad de "ver un afuera", se convierte en un paradigma inmunológico (Han, 2017), pero, a su vez, se desenvuelve en un circuito de mecánica cíclica e ilimitada de placer, -excitación, descarga y consumo-, que repite su ciclo y termina agotando al propio agente. Así, en este orden de ideas, sostiene Han (2020) que no consumimos sólo objetos, sino también las emociones que éstos nos sugieren, puesto que no se pueden consumir perpetuamente los objetos, pero sí las emociones que estos generan. De ahí que para el filósofo coreano (2020) el consumo de la emoción intensifica la referencia narcisista. 
Empero, la figura del progreso en la modernidad acaece en su doble condición: por un lado, liberadora, pero también en su sentido opuesto, como la edificación y el diseño de un mecanismo sofisticado de relaciones de ratificación, normalización y disciplinamiento. Así, el saber equivale al poder, tal como había mencionado la crítica frankfurtiana, en tanto que el saber se disuelve en sustrato de dominio (Horkheimer y Adorno, 2005), en el que los artefactos tecnológicos devienen formas de concentración del saberpoder, disciplinamiento y confección de la subjetividad.

\section{El panoptismo digital}

Foucault describe en su obra Surveiller et Punir de 1975, la idea del panóptico, la cual está fundada en el proyecto benthamiano de la reforma de las prisiones. Se trata de una edificación arquitectónica que maximiza los recursos de la vigilancia, procura el control, facilita los saberes. Dicha mole de concreto consistía en una torre central que fungía en términos de panóptico y que, bajo el concurso de sus particularidades arquitectónicas, permitía vigilar a los reos, sin que el vigía fuera visto por estos. Esta arquitectura significaba un juego de luces y sombras que potencializaba el diseño del edificio que fracturaba el binomio óptico ver-ser visto. De esta manera, la vigilancia se interiorizaba en la mente del reo y dicha subjetividad suplía al vigía concreto. Semejante operación, siguiendo a Foucault, permitía condicionar los movimientos del preso, también sus deseos y motivaciones, evitando la mala conducta; brindaba asimismo la posibilidad de disipar todo intento de fuga ante la mirada siempre oculta y furtiva del celador que se había interiorizado (2013b).

El panóptico representa el desplazamiento de una vieja mole de construcción punitiva, por el de una arquitectura más ergonómica para su función, como señala Foucault (2013b). La prisión es sustituida por una geometría simple y económica que representa una "casa de convicción". Así, el reo deviene sospechoso y juez en un mismo movimiento. El poder aligera su peso, deviene más sutil e ingrávido, imperceptible (2013b); genera una atmósfera que crea orientaciones y dependencias, provee estímulos que confeccionan las acciones y concepciones, es decir, se trata de un andamiaje que constituye la subjetividad exocerebral. El concepto de panóptico alude, en su dimensión social, a una serie de prácticas culturales, económicas, políticas, a racionalidades que incluyen mecanismos de ratificación y disciplinamiento 
que apuntan a la gestión de la vida y al control de la subjetividad: biopolíticas. Estas formas biopolíticas sostienen el poder que ejerce la dinámica social reticularmente sobre los individuos.

Otro de los autores que actualiza el concepto de la biopolítica foucaltiana es Byung Chul-Han (2014), en términos del control que se opera desde la intervención de los instrumentos digitales y fenómenos como el de Big Data $^{6}$. Han (2014) sostiene que el Big Data asemeja al funcionamiento de un panóptico, mediante la sustitución del vigía material por algoritmos complejos y automáticos que cartografían a los usuarios, sujetos, industria etc. Han también describe el funcionamiento integral inherente a la sociedad de comunicación, formas de consumo, inclinaciones políticas etc., mediante el instrumento de los datos. Empero, lo que para Han permite este mecanismo de vigilancia, ver sin jamás ser visto, operar una serie de técnicas, -desde el poder-saber, mediante un reticulado algorítmico- es que cartografían pormenorizadamente a los individuos mediante la potencia biopolítica del algoritmo. De esta manera se internaliza un tipo de subjetividad que impone una serie de inclinaciones y demandas; una maniobra de control y dominio que se mueve desde la esfera de la información y los deseos (2014). Se trata de una ascesis - configuración y normalización-mediante formas biopolíticas y psicopolíticas, en la que la ejecución del poder se gesta a través de la persuasión y el hedonismo; operación que coincide en un mismo agente, lo cual asemeja al sujeto automático marxista, que ejerce una soberanía diferente de sí (2017) y ejecuta, más bien, una soberanía ilusoria del tipo narcisista.

\section{El cuidado de sí como una forma de resistencia}

La obra de Foucault, como declara en Las palabras y las cosas, remite a la forma en la que los discursos entran en una dinámica de juegos de verdad, puesto que estos se insertan en una estructura de saberes o modelos científicos que validan la experiencia, tal como sucede en el caso de la psiquiatría y del sistema penitenciario. Sin embargo, hay una gran variedad de juegos discursivos que fungen en términos de orientación y génesis de sentido que articulan y posibilitan la subjetividad válida. Se trata de mecanismos de

6 Para profundizar en el fenómeno del Big Data como estructura que asemeja a un panóptico, que emplea relaciones de ratificación con base en un entramado de información que cartografía apuradamente la silueta del sujeto e impone una serie de motivaciones y demandas cfr. Harari (2017). 
coherencia que internalizan formaciones y conocimientos, lo cual apunta a una dimensión biopolítica; juegos de verdad que representan un circuito de validación que deviene finalmente "casa de convicción". Asimismo, tales mecanismos de coherencia representan una disposición y faro del sentido y el sinsentido, de lo válido e inválido. Lo anterior apunta a la constitución de un ethos, fundado en la síntesis social que encuentra en su centro las formas psíquicas del capital: narcisismo, fetichismo de la mercancía, etc. No obstante, Foucault hace referencia a cierto tipo de ejercicios de resistencia que se gestan desde la dimensión ética; alude a una tecnología del yo. Se refiere a un fenómeno que identifica como "práctica de sí", la cual era bastante importante en las sociedades antiguas, tales como la griega y romana, que hacían hincapié en las formas de autonomía y autarquía. Lo anterior hace referencia a una "práctica de sí" elevada a arte de la existencia, de la cual la tradición hace hincapié en la formación de los individuos. "Práctica de sí" descartada cada vez más en la actualidad por el sujeto en la construcción de su subjetividad. De este modo el sujeto contemporáneo delega para la confección de su subjetividad a agentes externos como el mercado, la macroestructura económica y sus dispositivos de alienación. A propósito del saber Foucault señala acerca del cuidado de sí que éste estaba elevado a categoría de arte de la existencia:

Se puede caracterizar brevemente esta cultura del "cuidado de sí" por el hecho de que el arte de la existencia -technē tou biou bajo sus diferentes formasse encuentra dominado aquí por el principio de que es necesario "cuidar de uno mismo", principio de cuidado de sí, el que funda su necesidad, ordena su desarrollo y organiza su práctica. Pero es necesario precisar la idea de que hay que aplicarse a uno mismo, ocuparse de uno (heautou epimeleisthai) es un tema muy antiguo en la cultura griega. Surgió desde el principio como un imperativo altamente aceptado. El Ciro ideal de Jenofonte, no considera que su existencia esté agotada a raíz de sus conquistas, porque le falta lo más precioso, ocuparse de sí mismo. "No podemos reprochar a los dioses no haber cumplido todos nuestros deseos", dijo, pensando en sus pasadas victorias (...) Un aforismo lacedemonio, contado por Plutarco, afirmaba que la razón por la que se había confiado el cuidado de la tierra a los ilotas, era que los espartanos querían por su parte, "ocuparse de sí mismos", sin duda era el entrenamiento físico y guerrero lo que designaban de ese modo. Pero es en un sentido enteramente diferente en el que se emplea en la expresión de Alcibíades, el que constituye un tema esencial del diálogo: Sócrates muestra al ambicioso joven que es muy presuntuoso de su parte querer tomar a su 
cago la ciudad (...) si no ha aprendido previamente lo que es necesario saber para gobernar: primero debe cuidarse a sí mismo (...). Y en la Apología, en cuanto maestro del cuidado de sí como Sócrates, se presenta a sus jueces: "un dios le ha ordenado recordar a los hombres que deben preocuparse, no por su riqueza, no de su honor, sino de ellos mismos, y de sus almas" (2013a, pp. $48-49)^{7}$.

El cuidado de sí implica un apartamiento de los juegos de verdad que operan en términos de dispositivos de disciplinamiento, por ejemplo, la alienación del sujeto automático marxista, las economías psíquicas que articulan la subjetividad, etc. El cuidado de sí implica un tipo de saberes de la autotransformación del sujeto, buscando otro modo de ser. Implica alcanzar la virtud allende de los valores alienantes de la actualidad, con los cuales se sustenta toda inteligibilidad contemporánea, con los que opera el ciclo del capital y sus formas de validación. Foucault (1984) sostiene que el adiestramiento ético es una práctica ascética, “(...) no en el sentido de la moral de la renuncia, sino de un ejercicio de uno sobre sí mismo" (p. 258), ya que este ejercicio apunta a un sujeto que intenta elaborarse, transformarse, es decir, que demanda un trabajo sobre sí, ulterior del contorno de legitimidad de los juegos de verdad y de las demandas "de la casa de convicción panóptica". En cierto modo se trata de tomar la vida como una obra de arte, como un proceso creativo de transformación individual; obra de arte que reclama articularse allende de los mecanismos de la "verdad", del mercado y sus instrumentos de alineación. Dicha formulación ética apela, más bien, a definir una serie de tecnologías del yo, que confeccionan la subjetividad atendiendo la preocupación de sí. Esta confección se desenvuelve más allá de las relaciones de validación y disciplinamiento (2013b), lo cual significa, quizá, ser el único sentido de liberación a través del cuidado de sí y sus cristalizaciones éticas en el entramado social. En este contexto, la ética para Foucault representa un cuidado de sí como práctica de la libertad y, asimismo, la libertad adviene condición ontológica de la ética (1984). La dimensión ética en Foucault abre entonces el campo para nuevas relaciones sociales, partiendo de una serie de prácticas liberadoras. El cuidado de sí es una práctica antigua de las tradiciones grecolatinas, como sostiene Foucault (1984), en tanto que la ética se desenvuelve como único horizonte de resistencia y potencial utopía para devenir otras sociedades y mundos posibles, más allá de las formas totalitarias de configuración del capital.

7 Traducción del autor del presente artículo. 


\section{Conclusión}

Para Foucault, la ética en el mundo antiguo tiene que ver con alcanzar la virtud individual, no solamente a nivel de la polis o la civitas. Se trata de implementar prácticas como la prudencia, la virtud, etc. (Foucault, 1984). El ocuparse de sí mismo -entendido en términos de Foucault- será por tanto lo opuesto al narcisismo que representa una forma patológica de apego a sí mismo en la que no existe, en términos generales, una relación verdadera de objeto. En este sentido, la forma psíquica narcisista representa un paradigma inmunológico en el que no opera la auténtica alteridad. Los objetos exteriores, en este caso, surgen como una extensión del yo, de la pulsión y los deseos. Así, estas formas psíquicas contemporáneas, para autores como Jappe (2019), representan los mecanismos epítomes de la economía psíquica, que advienen modelos de orientación y sentido. Estos modelos son arquetipos que terminan disolviendo las formas de virtud y sabiduría de la antigüedad tales como la prudencia, aidos, diké, sophrosine, etc., tecnologías del yo que hacían hincapié en una ética de los límites y del equilibrio, frente a la desmesura de la tenaza técnica y de los mecanismos de producción de valor "ilimitado" de la actualidad.

El cuidado de sí busca la excelencia de los individuos, cercano a una ética de la virtud aristotélica. La excelencia humana se alcanzaba a través del conocimiento de sí, gnóthi seautón, de modo que para los griegos era necesaria la libertad para conducirse éticamente; ocuparse de sí para ganarse a sí mismo: "El cuidado de la libertad ha sido un problema esencial y permanente durante los ocho magnos siglos de la cultura antigua. Ahí se da toda una ética que gira en torno al cuidado de sí y que otorga a la ética clásica (...) este imperativo fundamental: "Cuídate de ti mismo" (Foucault, 1984, p. 262).

La dinámica del ethos remite a la manera de ser, de dirigirse, a los móviles de acción, siguiendo a Foucault, pero no solo en los movimientos, "a través de su vestir, de su aspecto, de su forma de andar, de la calma con la que respondía a todos los sucesos, etc." (1984). El cuidado de sí es la forma fenoménica que alcanza la libertad. Para que se manifestara en las tradiciones grecorromanas era necesario que el individuo se preocupara por la formación de un ethos, de una práctica de la libertad. Esta práctica de la libertad representaba una ascesis, es decir, una inversión y trabajo sobre sí mismo. Sin embargo, el 
cuidado de sí en tanto que arte de gobierno, como forma de autarquía, apela también al cuidado de los otros; dicho de otra forma, remite al funcionamiento y a la dinámica social, a la polis (1984). Lo anterior reclama, en cierto modo, una conversión, una transvaloración del tejido social; remite a la búsqueda de la autenticidad. No obstante, Foucault atiende dos graves riesgos que entraña la cultura griega: el primero es la esclavitud, pero también, como lo inverso de la esclavitud, el abuso del poder, que ya era sancionado en las tradiciones antiguas en términos de némesis; aquello que se opone a la armonía de los órdenes del cosmos físico y social (1984). Esto representa un discurso contestatario contra las concepciones modernas -formaciones como la lógica del mercado-, que hacen una aplicación del poder indebida; hybris. Así también, señala Foucault, en este orden de ideas, que los hombres pueden ser esclavos de sí, en tanto que persiguen únicamente el orden de sus apetitos (2013a). Conducirse con sobriedad representa, en consecuencia, la instrucción del bien soberano, puesto que aquel que ejerciendo dominio de sí ejerce su poder como es debido ante los otros, participa de una relación homeostática, es decir, ética (Foucault, 1984).

La función del capital introduce, sin embargo, una dinámica de lo ilimitado en el contorno planetario y social. Función del capital que concreta las formas de valor y articula también mecanismos que configuraran la subjetividad y sus formas de economía psíquica, sobreviniendo en formaciones que posibilitan toda inteligibilidad. En este contexto, para Foucault, la dimensión ética ya implica una afrenta y resistencia contra los esquemas fetichistas que fundamentan las formas de la subjetividad vigente. La ética cimienta de esta manera una sociogénesis que reclama relaciones de cuidado y contención, las cuales se introducen en el propio armazón de toda dinámica social. Éstas son formas reactivas que demandan la posibilidad de plantear otras prácticas, otros saberes, -cuidado de sí-, en tanto que cuidado de los otros. La ética, como cuidado de sí, reclama entonces orientaciones que abandonan el contorno de las guías configuradoras de sentido que moldean la subjetividad contemporánea; se trata de un ejercicio, de un ethos y, por tanto, de la precipitación de la libertad que se gesta como única posibilidad de utopía y progreso. Esto significa una afrenta contra los modelos dominantes, esgrimidos desde la lógica fetichista del capital, lo que implica devenir de otras lógicas más sustentables que posibiliten novedosas formas de organización, y que operen con el trasfondo de la ética como manifestación de la libertad. 


\section{Referencias}

Aragüés, A. (2013). Apuntes sobre la teoría del valor de Marx. Cuaderno de Materiales, 25, pp. 5-24. http://www.filosofia.net/materiales/pdf25/ teoria\%20del\%20valor.pdf

Arendt, H. (2014). Los orígenes del totalitarismo (G. Solana, Trad.). Madrid: Alianza.

Aristóteles (1988). Política. (M. García Valdés, Trad.). Madrid: Gredos.

Bauman, Z. (2003). La modernidad líquida (M. Rosenberg, Trad.). Buenos Aires: Fondo de Cultura Económica.

Bartra, R. (2014). Antropología del cerebro. Consciencia, cultura y libre albedrío. México: Fondo de Cultura Económica.

Dufour, D. (2007). Le Divin Marché. La révotution culturele et libérale. París: Gallimard.

Foucault, M. (1984). L'éthique du souci de soi comme pratique de la liberté (A. Gabilondo, Trad.). C. Gómez (Ed.), Doce textos fundamentales de la Ética del siglo XX (pp. 256-264). Madrid: Alianza.

Foucault, M. (2013a). Histoire de la sexualité III - Le souci de soi. Paris: Gallimard.

Foucault, M. (2013b). Surveiller et punir Naissance de la prison. Paris: Gallimard.

François, F. (2013). El crepúsculo de Prometeo: contribución a una historia de la desmesura humana (N. Sobregués, Trad.). Barcelona: Galaxia Gutenberg.

Freud, S. (1984). Introducción al narcisismo (J. L. Etcheverry, Trad.). Buenos Aires: Amorrortu.

Han, B. (2014). Psicopolítica (A. Bergés, Trad.). Barcelona: Herder.

Han, B. (2017). La sociedad del cansancio (A. Saratxaga y A. Ciria, Trads.). Barcelona: Herder.

Han, B. (2020). La desaparición de los rituales. Una topología del presente (A. Ciria, Trad.). Barcelona: Herder. 
Harari, Y. N. (2017). Homo Deus. Breve historia del mañana (R. Joandomènec, Trad.). México: Penguin Random House.

Horkheimer, M. y Adorno, Th. (2005). Dialéctica de la Ilustración (fragmentos filosóficos) (J. Sánchez, Trad.). Madrid: Trotta.

Jappe, A. (2019). La sociedad autófaga, capitalismo, desmesura y autodestrucción (D. Sanromán, Trad.). España: Pepitas.

Lacan, J. (2009). Escritos 1 (T. Segovia, Trad.). México: Siglo XXI.

Laplanche, J. y Pontalis, J. (1996). Diccionario de psicoanálisis (F. G. Cervantes, Trad.). Barcelona: Paidós.

Marx, K. (2010). El capital I. El proceso de producción del capital (P. Scaron, Trad.). Madrid: Siglo XXI.

Preciado, B. (2008). Testo yonqui. Madrid: Espasa Calpe.

Weil, S. (2014). Reflexiones sobre las causas de la libertad y de la opresión final (R. Blanco Vázquez, Trad.). Buenos Aires: Godot. 